\title{
ANN and RSM approach for modelling and multi objective optimization of abrasive water jet machining process
}

\author{
Srinath Reddy N. ${ }^{a}$, Dinesh Tirumala ${ }^{a}$, Rajyalakshmi Gajjela ${ }^{a^{*}}$ and Raja Das ${ }^{b}$
}

${ }^{a}$ School of Mechanical Engineering, VIT University, Vellore, Tamilnadu, India-632014

${ }^{b}$ School of Advanced Sciences, VIT University, Vellore, Tamilnadu, India-632014

\begin{tabular}{l}
\hline C H R O N I C L E \\
\hline Article history: \\
Received March 16, 2017 \\
Received in revised format: \\
October 20, 2017 \\
Accepted November 28, 2017 \\
Available online \\
November 28, 2017 \\
\hline Keywords: \\
AWJM \\
Response surface methodology \\
Artificial neural network \\
Modeling \\
Optimization \\
\end{tabular}

\section{A B S T R A C T}

\begin{abstract}
Abrasive Water Jet Machining is one of the novel nontraditional cutting processes found diverse applications in machining different kinds of difficult-to-machine materials. Process parameters play an important role in finding the economics of machining process at good quality. This research focused on the predictive models for explaining the functional relationship between input and output parameters of AWJ machining process. No single set of parametric combination of machining variables can suggest the better responses concurrently, due to its conflicting nature. Hence, an approach of Multi-objective has been attempted for the best combination of process parameters by modelling AWJM process using of ANN. It served a set of optimal process parameters to AWJ machining process, which shows a development with an enhanced productivity. Wide set of trail experiments have been considered with a broader range of machining parameters for modelling and, then, for validating. The model is capable of predicting optimized responses.
\end{abstract}

(C) 2018 Growing Science Ltd. All rights reserved.

\section{Introduction}

AWJ process is an advanced machining process for difficult to cut materials. Collision of abrasive material with water is used to erode the work piece material (Mishra, 2002). High pressure water mixes with abrasives in mixing chamber and this abrasive water jet coming through the nozzle cuts the workpiece material. This process is a well-known advanced technique for cutting difficult-to machine materials. It is a technique, which machines without heat generation and the machined surface is generated without any HAZ or residual stress virtually (Khan \& Haque, 2007) This process is inert towards properties of material with high versatile and flexible in machining. The main disadvantage of this technique is its vociferous and disordered working environment (Azmir \& Ahsan, 2009)

AWJ machining process is nonconformist yet totally a flexible process. Fret issue of high speed water jet combined with grating is used for metal removal. The intention of cutting by Waterjet is approved

* Corresponding author.

E-mail address: rajyalakshmimed@gmail.com ( R. Gajjela)

2018 Growing Science Ltd. doi: $10.5267 /$ j.dsl.2017.11.003 
from universe which has been exhibiting the incident of gnawing of the material by a flow of water. For the improvement in AWJ technology, when the fluid flow is combined with sand particles, the pace of erosion is viewed to be quicker. High speed waterjet is fabricated by crossing high tensioned water over a very tiny orifice during that time the abrasive is combined with high tensioned water in a blending cabin to produce abrasive jet. These complete cutting ends accommodated by water particles enlarge the percentage of gnawing, developing the machining proficiency of AWJ is very complex compared to pure WJ. The mechanism of material removal contains the following steps: micro cutting, micro-fracture and ploughing deformation. An imperious mechanism of metal cutting is detected by the features of influencing AW grains viz. physical dimensions of the workpiece, stiffness, the jet crash angle, feed rate. Micro cutting and pushing deformation are allied with plastic materials and shoal crash angles; where micro machining arise for spiny particles during which ploughing deformation is allied with round shaped particles. Micro cracking observes when the grains crash about right to the metal piece. Micro cutting is trusted to be the imperious mechanism for MRR in AWJ cutting of Fiber Reinforced Plastics (Folkes, 2009). Fig. 1 shows a simple schematic diagram of Abrasive Jet Machining (AJM). Pressurized jet may comprehend of an intensifier, prime mover, controller, and an accumulator. Pressurized water at $200-400 \mathrm{Mpa}$ is fed through high pressure jet tube to the module called cutting head. As described in Fig.1, the flow of water then carries along with a tiny hole (of $0.2-0.3 \mathrm{~mm}$ diameter) at high pressure, to frame a velocity $(200-300 \mathrm{~m} / \mathrm{s}) \mathrm{WJ}$ at very high rates. Water Jet is then entered inside the stirring cabin to blend by abrasives equipped by abrasive furnishing system forming it which exit from vent nozzle of comparably huge diameter with $0.7-0.8 \mathrm{~mm}$. CNC system is used for controlling the location and motion of the cutting head (Patel, 2013). AWJ machining includes utterly a small number of influential parameters that can show the impact on performance of AWJ cutting. Fig. 1 shows their general relationship. Moreover, main and easy-to-adopt parameters are considered approximately for obtaining the superior quality of the cut.

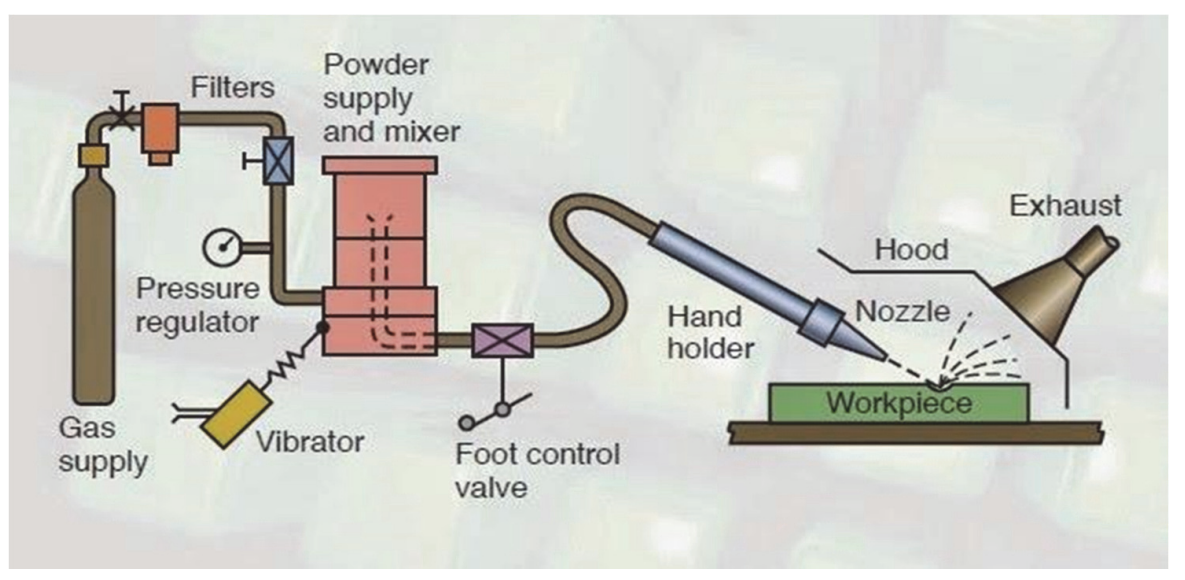

Fig. 1. A simple schematic diagram of Abrasive Jet Machining (AJM)

Due to its peculiar parameters and amusing features, such as invulnerability and encumbering to scratches, cracks, stains, spills, heat, cold, and moisture, granite has been extensively adopted as bounded stone in societal and economic applications in regular life (Zhao et al., 2013). AWJ is an advanced tool for penetrating rocks and rock like metals. It is best suited for cutting, pre-weakening and drilling of tough rocks (Momber \& Kovacevic, 1997). For production industries and also for other civil and mining engineering fields this process is an assured tool due to its exceptional properties of inflexible cutting, and acceptable surface roughness, minor kerf widths, expanded tool life, trouble freeform cutting, flexible process, dust free, ergonomic working conditions, and environment. These highlights make the process an ecofriendly process compared to other conventional machining processes like sawing (circular) in raw stone cutting and figuring areas (Assarzadeh et al., 2010; Vundavilli et al., 2012; Myers et al., 2016). 
There are abundant parameters associated with this process. The connected parameters of AWH machining process are figured out in Fig. 2. (Jegaraj \& Babu, 2007; Shanmugam et al., 2008). Many of the researchers have focused on understanding the effect of the most influential parameters on responses like material removal rate, surface roughness, kerf and microstructural properties. Very few researchers have been suggested techniques for enhancing the surface finish and kerf quality (Shanmugam \& Masood, 2009; Lemma et al., 2002). Based on a thorough knowledge of the AWJC metal removal mechanism, various methods such as polishing (Fenggang et al., 1996), turning (Hashish, 1987), drilling (Yong \& Kovacevic, 1997), milling (Hashish, 1989) and surface finishing (Borkowski, 2004) have been progressed to design and machine economically.

Earlier commented, AWJ machining process has about no boundaries. This process is highly preferable for $2 \mathrm{D}$ and $3 \mathrm{D}$ machining. There is no variation between cutting of cheap construction steel or stainless steel materials, both are equally machined well. If quality is highly demanded during machining process, the process parameters (Fig. 2) must be properly selected and the machining process needs to be ended before occurrence of the abrasion deformation section. Parameter optimization for higher material removal and recommended surface roughness was done out by (Nagdeve et al., 2012). Taguchi's integrated with ANOVA were adopted for optimization. The analysis exhibits that the standoff distance affects the MRR whereas surface roughness was highly influenced by abrasive flow rate. (Ramprasad \& Kamal, 2015) investigated that the water pressure was the most influential factor for stainless steel 403 work material followed by standoff distance and abrasive flow rate.

Liu et al. used (2014) response surface methodology (RSM) with Box-Behnken Design (BBD). The outcomes concluded that the transverse speed is an influential factor along with water pressure, abrasive flow rate and tilt angle. AWJ process was optimised using DOE with statistical approach (Ibraheem et al., 2015). The results showed that the suitable set of process parameters were responsible for the enhanced quality of finishing, dimension accuracy, and for higher productivity. An ANN model was developed to guess the speed of cut to the promised surface quality during AWJM (Lu et al., 2005). Forecasting of depth of cut using neural network model is build published a paper on genetic neuro technique stating that neural network model to predict cut depth is introduced by considering focusing nozzle diameter, rate of jet traverse, water pressure and abrasive flow rate. ANN combined with GA, i.e. genetic neuro technique, is showcased for suggesting the optimal set of input parameters (Srinivasu et al., 2005). A start has been done to build ANN model and Fuzzy logic for different figuring area employing AWJC along with an idea of focusing nozzle diameter (Srinivasu \& Babu, 2008).

\subsection{Motivation and objective of the work}

The researchers have, even, donated towards exposure of ABWJ machining process. Moreover investigation is being continued still. This crucial, predictive control and performance of the grinding process. Optimization is certainly one of the aspects. Surface roughness and material removal rate are the most important responses while considering AWJ machining process proposes the need of future research. Further and continued research may gush through several aspects of more 


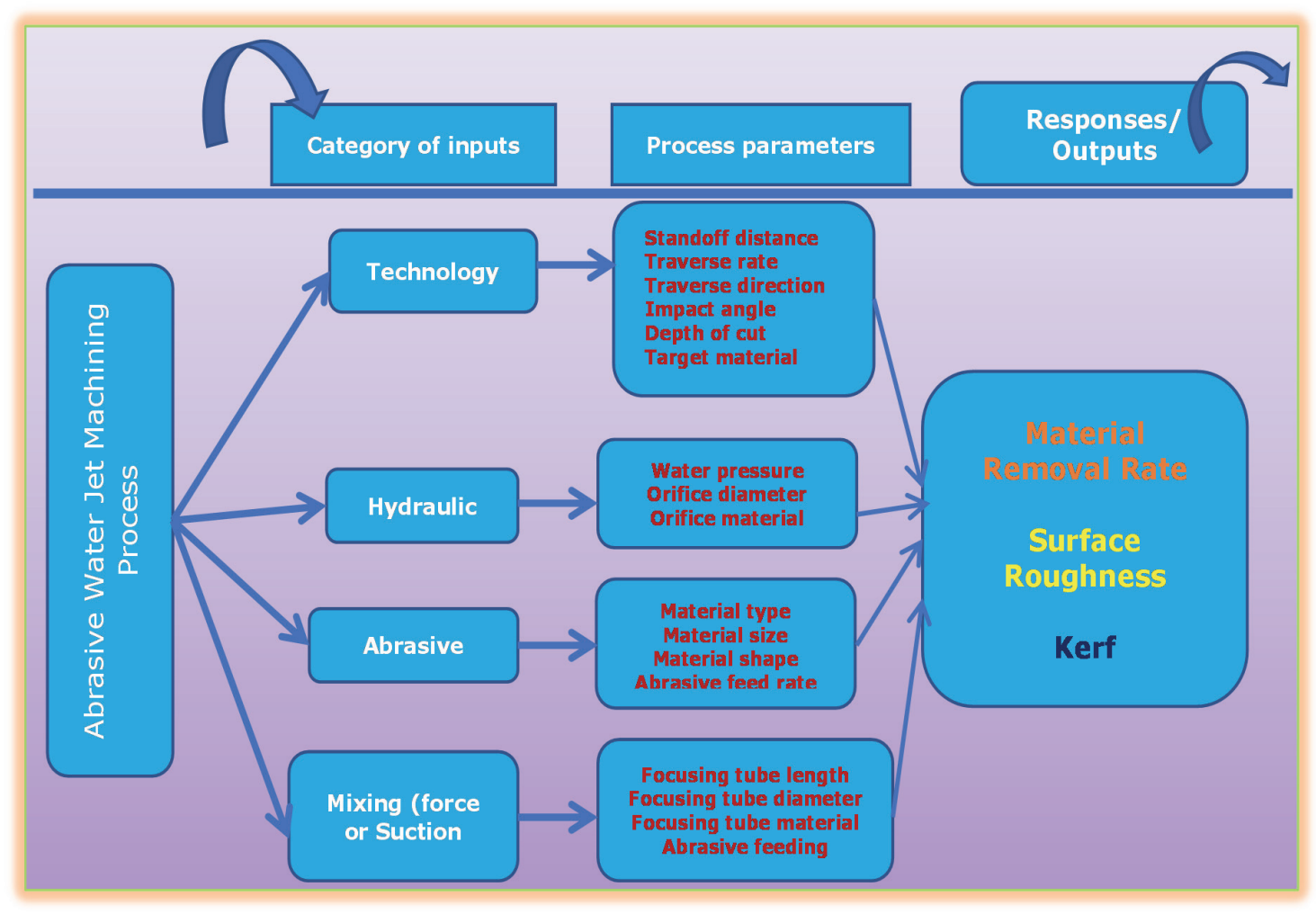

Fig. 2. Process parameters and responses in AWJ process

In addition, process variables are anticipated to influence surface roughness, as well as material removal rate during AWJ machining process. Taking in to account the aspects, the current work has been done to analyze how the assorted process parameters impact on surface roughness and material removal rate in AWJ machining of granite material. Multi objective optimization has been attempted by considering simultaneous minimization of surface roughness and maximization of material removal rate. The observation has been done through experiments; data examined using RSM and ANN approach. Mathematical modeling has also been done, to determine the relation between the responses and process parameters. It is predicted that this work and future research in this area will finally direct to build a vigorous knowledge and database, this may facilitate proper selection of process parameters more reliably and predictively for people in industry to achieve the desired performance in abrasive water jet machining of granite. This work is targeted on predicting responses of AWJ process parameters for machining a granite material applying RSM and ANN and also to optimize the process for qualitative productivity.

\section{Experimentation}

Abrasive water jet machining has been carried out at various levels of process variables as per BoxBehnken design matrix, which is deliberated subsequently. An abrasive jet begin out the like a pure water jet. As the lean flow of water leaves the nozzle, abrasive is joined to the stream and blended. The beam of water precipitates abrasive particles to speeds higher in order to cut much harder materials. The blending of abrasive particles in water jet is in such a way that water jets momentum is shifted to the abrasives. The coherent, abrasive water jet that exists the AWJM nozzle can cut various materials, such as metals, glass, ceramics, and composites. The work material (Fig. 3) used in this experiment is granite machined into 27 samples of $2 \mathrm{~cm} \times 2 \mathrm{~cm}$ dimension. Each experiment is repeated twice and average of response values are considered for analysis. 


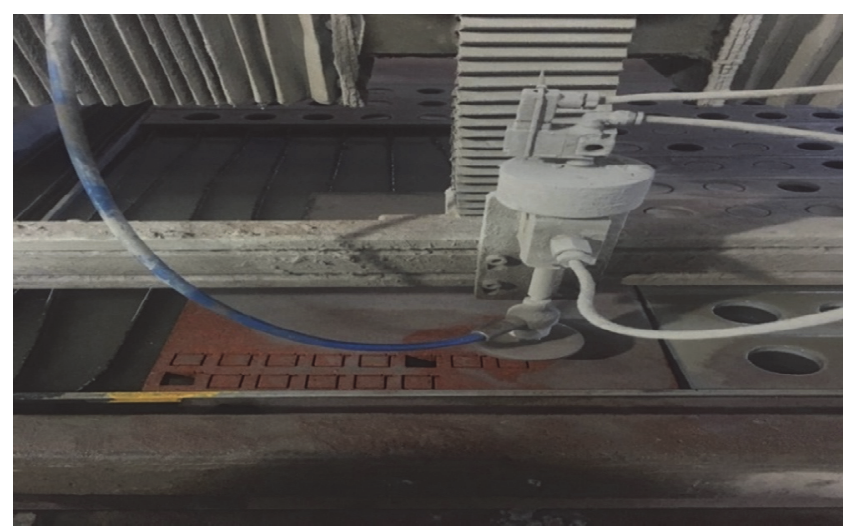

Fig. 3. Granite cutting using AWJM

\subsection{Experimental Design}

\subsubsection{Response Surface Methodology}

A response surface (Box \& Draper, 2007) design is a set of futuristic design of experiments (DOE) techniques that help you comprehend and is optimize your response in a better manner. Response surface methodology is frequently applied to cultivate models after most influential factors have been determined using factorial designs. If a response of interest is influenced by multiple variables RSM is one of the best techniques for modeling and analysis because it is a combination of both mathematical and statistical technique, and then the target is the optimization of output by simultaneous variation of input factors. RSM is one of the operative techniques for enhancing, improving and optimizing the machining process by joining various process parameters and to decide the impact of critical interactions on the achievement of the output variables. For adopting RSM, choice of range of process parameters and effective design of experiment is in need. In present work, model built by adopting design of experiment with Box Behnken design and regression analysis in addition with ANOVA for judging about the performance of the model. The responses were modelled to equip quadratic pattern depicted by the given equation.

$$
Y=\beta_{0}+\beta_{1} x_{1}+\beta_{2} x_{2}+\beta_{3} x_{3}+\beta_{12} x_{1} x_{2}+\beta_{13} x_{1} x_{3}+\beta_{23} x_{2} x_{3}+\beta_{11} x_{1}^{2}+\beta_{22} x_{2}^{2}+\beta_{33} x_{3}^{2} .
$$

Here the notations with $\beta$ are called approximating function parameters. $Y$ is an output parameter, and $x$ is process parameter. In this work, all 27 experiments (Table 2) were planned based on Box Behnken method. Four process parameters (Table 1) were considered for evaluating the performance of machining process. The responses considered for evaluation are material removal rate (MRR) and surface roughness $\left(R_{a}\right)$. Experiments were conducted according to the order suggested by RSM methodology and the results were calculated as per the below formula and recorded in Table 3 .

$$
\begin{aligned}
& M R R=H_{t} W D_{i} \\
& H_{t}=\text { depth of penetration } \\
& V_{f}=\text { Traverse speed of the abrasive water jet } \\
& W=\text { width of the kerf }
\end{aligned}
$$

$$
\begin{aligned}
& \mathrm{H}_{\mathrm{t}}=16.5 \mathrm{~mm} \\
& \mathrm{~V}_{\mathrm{f}}=\text { varies at three different levels } \\
& \mathrm{W}=\text { varies depending on the kerf value }
\end{aligned}
$$

Kerf width is calculated using Vernier caliper. Surface roughness of the samples is found using roughness testing machine.

\section{Table 1}

Process parameters and their levels

\begin{tabular}{ccccc}
\hline Level & $\begin{array}{c}\text { Pressure } \\
\text { (bar) }\end{array}$ & $\begin{array}{c}\text { Abrasive } \\
(\mathbf{g m} / \mathbf{m i n})\end{array}$ & $\begin{array}{c}\text { Stand-off } \\
(\mathbf{m m})\end{array}$ & $\begin{array}{c}\text { Feed rate } \\
(\mathbf{m m} / \mathbf{m i n})\end{array}$ \\
\hline-1 & 3000 & 500 & 2 & 350 \\
0 & 3200 & 600 & 2.5 & 400 \\
1 & 3600 & 800 & 3 & 495 \\
\hline
\end{tabular}


Table 2

Box Behnken Experimental design

\begin{tabular}{|c|c|c|c|c|}
\hline S.NO & Pressure (bar) & Abrasive (gm/min) & Stand-off (mm) & Feed rate $(\mathrm{mm} / \mathrm{min})$ \\
\hline 1 & 0 & -1 & 0 & 1 \\
\hline 2 & 0 & 0 & 0 & 0 \\
\hline 3 & 0 & 1 & 0 & -1 \\
\hline 4 & -1 & 1 & 0 & 0 \\
\hline 5 & 0 & 0 & -1 & -1 \\
\hline 6 & 1 & 0 & 0 & -1 \\
\hline 7 & 1 & 0 & 0 & 1 \\
\hline 8 & 1 & 0 & -1 & 0 \\
\hline 9 & 0 & 1 & 0 & 1 \\
\hline 10 & -1 & 0 & 0 & -1 \\
\hline 11 & 0 & 0 & -1 & 1 \\
\hline 12 & 0 & 1 & 1 & 0 \\
\hline 13 & 0 & -1 & 1 & 0 \\
\hline 14 & 0 & 0 & 0 & 0 \\
\hline 15 & 0 & -1 & 0 & -1 \\
\hline 16 & -1 & -1 & 0 & 0 \\
\hline 17 & 0 & 0 & 1 & 1 \\
\hline 18 & -1 & 0 & -1 & 0 \\
\hline 19 & 0 & 1 & -1 & 0 \\
\hline 20 & 1 & 1 & 0 & 0 \\
\hline 21 & 0 & -1 & -1 & 0 \\
\hline 22 & 0 & 0 & 1 & -1 \\
\hline 23 & 1 & -1 & 0 & 0 \\
\hline 24 & 1 & 0 & 1 & 0 \\
\hline 25 & -1 & 0 & 1 & 0 \\
\hline 26 & -1 & 0 & 0 & 1 \\
\hline 27 & 0 & 0 & 0 & 0 \\
\hline
\end{tabular}

Table 3

Experimental Results

\begin{tabular}{|c|c|c|c|c|c|c|c|}
\hline S.No & $\begin{array}{c}\text { Pressure } \\
\text { (bar) }\end{array}$ & $\begin{array}{l}\text { Abrasive } \\
\text { (gm/min) }\end{array}$ & $\begin{array}{c}\text { Stand-off } \\
(\mathrm{mm})\end{array}$ & $\begin{array}{l}\text { Feed rate } \\
(\mathrm{mm} / \mathrm{min})\end{array}$ & $\begin{array}{l}\text { Kerf } \\
(\mathbf{m m})\end{array}$ & $\begin{array}{c}\text { SR } \\
(\mu \mathrm{m})\end{array}$ & $\begin{array}{c}\text { MRR } \\
\left(\mathrm{mm}^{\wedge} 3 / \mathrm{min}\right)\end{array}$ \\
\hline 1 & 3200 & 500 & 2.5 & 495 & 0.17 & 6.3496 & 528 \\
\hline 2 & 3200 & 600 & 2.5 & 400 & 0.43 & 5.2516 & 150.15 \\
\hline 3 & 3200 & 800 & 2.5 & 350 & 0.1 & 6.0605 & 528 \\
\hline 4 & 3000 & 800 & 2.5 & 400 & 0.3 & 7.9998 & 2376 \\
\hline 5 & 3200 & 600 & 2 & 350 & 0.15 & 6.2907 & 3185.325 \\
\hline 6 & 3600 & 600 & 2.5 & 350 & 0.026 & 4.9293 & 4290 \\
\hline 7 & 3600 & 600 & 2.5 & 495 & 0.39 & 7.3537 & 1388.475 \\
\hline 8 & 3600 & 600 & 2 & 400 & 0.08 & 6.9946 & 2838 \\
\hline 9 & 3200 & 800 & 2.5 & 495 & 0.08 & 6.0177 & 1122 \\
\hline 10 & 3000 & 600 & 2.5 & 350 & 0.01 & 6.5055 & 303.6 \\
\hline 11 & 3200 & 600 & 2 & 495 & 0.09 & 5.6061 & 735.075 \\
\hline 12 & 3200 & 800 & 3 & 400 & 0.1 & 6.0196 & 792 \\
\hline 13 & 3200 & 500 & 3 & 400 & 0.09 & 5.8027 & 594 \\
\hline 14 & 3200 & 600 & 2.5 & 400 & 0.046 & 7.0307 & 130.68 \\
\hline 15 & 3200 & 500 & 2.5 & 350 & 0.27 & 6.1613 & 1559.25 \\
\hline 16 & 3000 & 500 & 2.5 & 400 & 0.32 & 7.2511 & 577.5 \\
\hline 17 & 3200 & 600 & 3 & 495 & 0.016 & 5.5828 & 653.4 \\
\hline 18 & 3000 & 600 & 2 & 400 & 0.13 & 6.7500 & 660 \\
\hline 19 & 3200 & 800 & 2 & 400 & 0.17 & 5.9860 & 866.25 \\
\hline 20 & 3600 & 800 & 2.5 & 400 & 0.08 & 6.4728 & 693 \\
\hline 21 & 3200 & 500 & 2 & 400 & 0.12 & 6.2216 & 924 \\
\hline 22 & 3200 & 600 & 3 & 350 & 0.12 & 5.3928 & 198 \\
\hline 23 & 3600 & 500 & 2.5 & 400 & 0.36 & 6.1543 & 81.675 \\
\hline 24 & 3600 & 600 & 3 & 400 & 0.65 & 6.1904 & 57.75 \\
\hline 25 & 3000 & 600 & 3 & 400 & 0.03 & 6.0323 & 1980 \\
\hline 26 & 3000 & 600 & 2.5 & 495 & 0.01 & 6.4509 & 858 \\
\hline 27 & 3200 & 600 & 2.5 & 400 & 0.14 & 6.4300 & 2112 \\
\hline
\end{tabular}

\subsection{Empirical Model formulation}

RSM has been implemented to calculate MRR and surface roughness of granite material during AWJ machining process. Box Behnken design of 27 experiments are considered establishing the model for 
formulation of relationship between responses and process parameters. Quadratic model for surface roughness and material removal rate are framed based on Eq. (2) and Eq. (3).

Following equations shows the response surface equation for surface roughness and material removal rates in terms of process variables.

$\mathrm{MRR}=1355+481 \mathrm{~A}-275 \mathrm{~B}+139 \mathrm{C}+189 \mathrm{D}+277 \mathrm{~A} \times \mathrm{A}+27 \mathrm{~B} \times \mathrm{B}-332 \mathrm{C} \times \mathrm{C}$

$-506 \mathrm{D} \times \mathrm{D}-429 \mathrm{~A} \times \mathrm{B}+1106 \mathrm{~A} \times \mathrm{C}+753 \mathrm{~A} \times \mathrm{D}-66 \mathrm{~B} \times \mathrm{C}+62 \mathrm{~B} \times \mathrm{D}-108 \mathrm{C} \times \mathrm{D}$

Regression Equation of surface roughness

$$
\begin{aligned}
& \mathrm{SR}=62374-2412 \mathrm{~A}+513 \mathrm{~B}-2357 \mathrm{C}+1684 \mathrm{D}+4929 \mathrm{~A} \times \mathrm{A}+1694 \mathrm{~B} \times \mathrm{B}-2840 \mathrm{C} \times \mathrm{C} \\
& -3051 \mathrm{D} \times \mathrm{D}-1076 \mathrm{~A} \times \mathrm{B}-216 \mathrm{~A} \times \mathrm{C}+6198 \mathrm{~A} \times \mathrm{D}+1131 \mathrm{~B} \times \mathrm{C}-578 \mathrm{~B} \times \mathrm{D}+2186 \mathrm{C} \times \mathrm{D}
\end{aligned}
$$

\section{Results and Discussion}

Based on response surface analysis, the impact of process variables on responses are discussed in this section.

\subsection{Effect on Process parameters on Surface roughness}

The goodness-of-fit in regression and ANOVA is examined by residual plots. Studying residual plots assists to find whether the ordinary least squares assumptions are being rescued. If these assumptions are fulfilled, then ordinary least squares regression will generate unbiased coefficient estimates with the least possible deviation. The normal plot of residuals is used to check the assumption that the residuals are normally distributed. The plot of residuals versus fits is used to check the assumption that the residuals have a fixed variance.

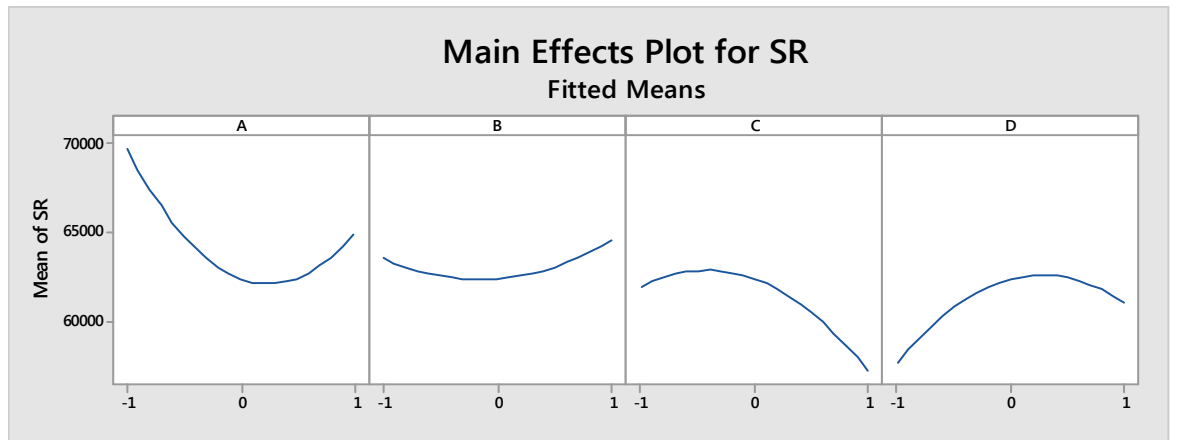

Fig. 4. Main Effects Plot for SR

It is clear that surface roughness (Fig. 4) is mainly influenced by pressure then by SOD and feed rate in the sequence. Surface roughness decreases with growth in standoff distance. High surface finish is obtained at low feed rate and high standoff distance. An optimal value of surface roughness of 5-6 $\mu \mathrm{m}$ is obtained at $3 \mathrm{~mm}$ standoff distance and at a feed rate of $350 \mathrm{~mm} / \mathrm{min}$. At low pressure and low abrasive flowrate surface roughness expected at very high rate. Non influential interaction terms have been eliminated. The accuracy of model in terms of the three tests, and analysis for lack of fit is verified by ANOVA. The standard of degree of fit is represented by coefficient of determination (R-sqr). The statistics of R-squared values clearly exhibits that, the pattern elucidates $92.2 \%$ of the total deviation. The obtained $\mathrm{R}^{2}$ value after calibrated for measure of the model is $85.39 \%$, smaller than permissible variation betwixt $R$-sqr and $R$-adj sqr. When comparing $R^{2}{ }_{\text {ddj }}=0.8539$ with $R^{2}$ pred $=0.4692$ explains both the terms are mutually covenant with one other and the pattern would be demanded to justify $46.93 \%$ variability in new data. Fairness of the suggested model in RSM is inspected by residual reports. Plots of all residuals of surface roughness have represented by Fig. 5 . 


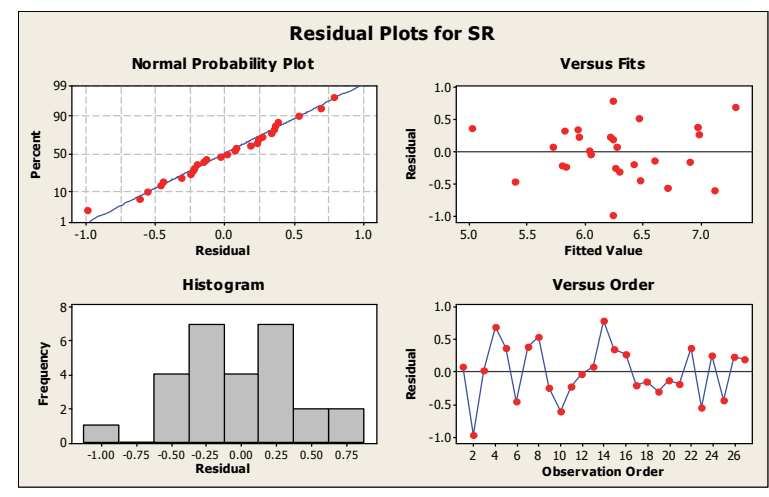

Fig. 5. Residual plots of SR

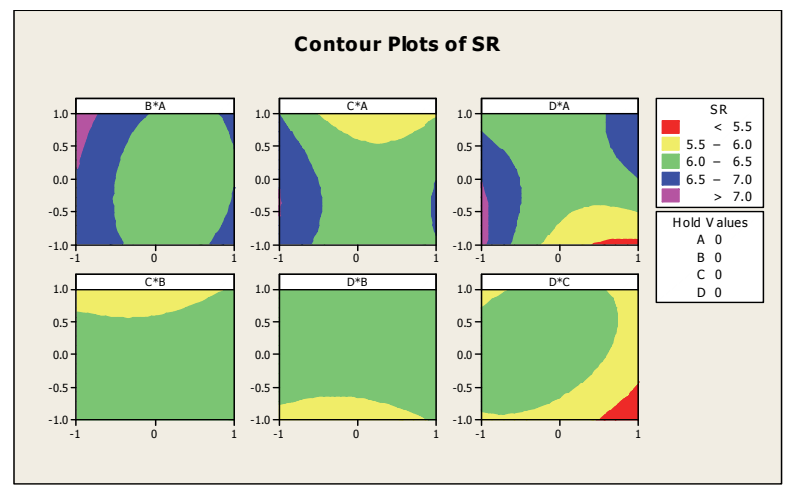

Fig. 6. Contour Plots of SR

It gives the information about errors and assumptions considered in this research. Proximity of points to the linear line denotes that assumptions are not offended, since errors are normally and independently distributed. Residual versus run number plot (Fig. 5) explains that there is no complicated pattern and unused structure, which uncovers that separate and fixed deviated assumptions are not opposed and no correlation betwixt residuals has been noticed. Since actual and predicted values lies on a straight line Fig. 5 denotes that the normal distribution of errors. The above explanation concludes the abundancy of the suggested model. There is no reason existed to suspect any violator of independence or fixed variation assumptions. A contour plot provides (Fig. 6) a 2-dimensional view of the surface where points that have the same response are connected to produce contour lines of constant responses. Contour plots are useful for establishing the response values and operating conditions.

Table 4

Analysis of Variance of SR

\begin{tabular}{cccccc}
\hline Source & DF & Adj SS & Adj MS & F-Value & P-Value \\
\hline Regression & 14 & 7.13283 & 0.50949 & 1.34 & 0.310 \\
\hline Linear & 4 & 1.73670 & 0.43418 & 1.14 & 0.384 \\
$\mathbf{A}$ & 1 & 0.69818 & 0.69818 & 0.83 & 0.201 \\
$\mathbf{B}$ & 1 & 0.03160 & 0.03160 & 1.75 & 0.778 \\
$\mathbf{C}$ & 1 & 0.66665 & 0.66665 & 0.89 & 0.210 \\
$\mathbf{D}$ & 1 & 0.34027 & 0.34027 & 2.33 & 0.115 \\
\hline Square & 4 & 3.55586 & 0.88897 & 3.40 & 0.090 \\
$\mathbf{A} \times \mathbf{A}$ & 1 & 1.29556 & 1.29556 & 0.40 & 0.538 \\
$\mathbf{B} \times \mathbf{B}$ & 1 & 0.15305 & 1.5305478 & 1.13 & 0.309 \\
$\mathbf{C} \times \mathbf{C}$ & 1 & 0.43023 & 0.43023 & 1.30 & 0.276 \\
$\mathbf{D} \times \mathbf{D}$ & 1 & 0.49649 & 0.49649 & 0.81 & 0.585 \\
\hline Interaction & & 1.84027 & 0.30671 & 0.12 & 0.733 \\
$\mathbf{A} \times \mathbf{B}$ & 1 & 0.04627 & 0.04627 & 0.00 & 0.945 \\
$\mathbf{A} \times \mathbf{C}$ & 1 & 0.00187 & 0.00187 & 4.04 & 0.068 \\
$\mathbf{A} \times \mathbf{D}$ & 1 & 1.53636 & 1.53636 & 0.13 & 0.720 \\
$\mathbf{B} \times \mathbf{C}$ & 1 & 0.05119 & 0.05119 & 0.04 & 0.855 \\
$\mathbf{B} \times \mathbf{D}$ & 1 & 0.01335 & 0.01335 & 0.50 & 0.492 \\
$\mathbf{C} \times \mathbf{D}$ & 1 & 0.19123 & 0.19123 & & 0.38 \\
\hline Residual Error & 12 & 4.5688 & 0.38074 & 0.891 \\
\hline Lack-of-Fit & 10 & 2.93066 & 0.29307 & 0.81911 & \\
\hline Pure Error & 2 & 16.3822 & & & \\
\hline Total & 26 & 11.7017 & & &
\end{tabular}

\subsection{Effect of process variables on MRR}

Fig. 7 describes a linear increase of MRR as pressure increases. Abrasive flow rate doesn't have any significant impact on MRR. Both SOD and traverse speed has similar impact on MRR. Fig 7 shows that maximum material removal rate can be achieved at high pressure and low SOD, traverse speed. Non influential interaction terms have been eliminated. The model accuracy which in terms consists of 
the three tests, i.e., significance of regression model, significance of model coefficients, and tests for lack of fit is verified by ANOVA (Table 5).

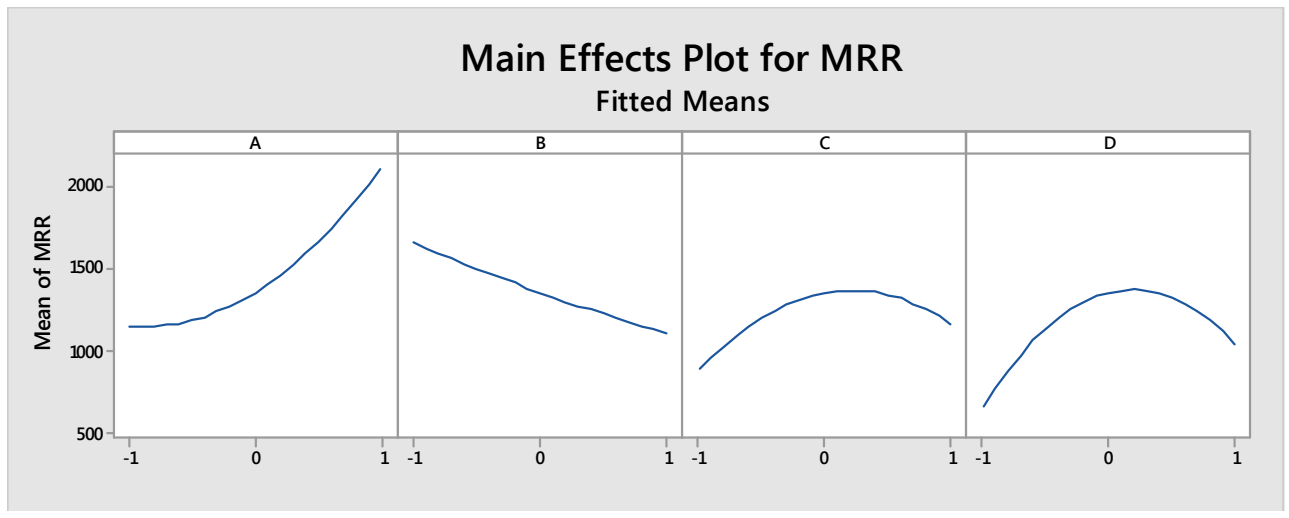

Fig. 7. Main effects plot for MRR

The standard of degree of fit is shown by coefficient of determination (R-squared). R-squared statistics clearly exhibits that the model explains $90.6 \%$ of the total deviation. The obtained $\mathrm{R}^{2}$ value after calibrated for size (terms) of model is $88.23 \%$, smaller than the permissible variation between $\mathrm{R}$ squared and adjusted $\mathrm{R}$-squared. Comparison of $\mathrm{R}^{2} \mathrm{Adj}=0.8826$ with $\mathrm{R}^{2}$ pred $=0.5273$ explains that both the terms are in mutual covenant with each other and the model would be demanded to justify $52.73 \%$ variability in new data. Fairness of the proposed model in RSM can be inspected by residual analysis. Plots of all residuals of surface roughness have represented by Fig 8. It gives the information about errors and assumptions considered in this research. Proximity of points to the straight line denotes that assumptions are not offended, since errors are normally and independently distributed. Residual versus run number plot (Fig. 8) explains that there is no complicated pattern and unused structure, which uncovers that separate and fixed deviated assumptions are not opposed and no correlation betwixt residuals has been noticed. Since actual and predicted values lies on a straight line Fig 8 denotes that the normal distribution of errors. The above explanation concludes the abundancy of the suggested model. There is no reason existed to suspect any violator of independence or fixed variation assumptions. It is concluded from counter plots (Fig. 9) that an optimum value of $2000-3000 \mathrm{~mm}^{\wedge} 3 / \mathrm{sec}$ of MRR can be achieved by setting pressure to $3600 \mathrm{bar}$, SOD $2 \mathrm{~mm}$ and traverse speed to $350 \mathrm{~mm} / \mathrm{min}$. MRR is observed to be minimum at low abrasive flow rate and high SOD, traverse speed.

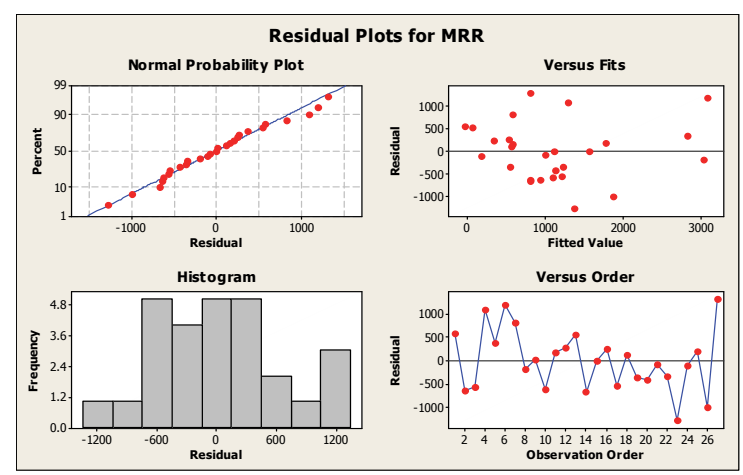

Fig. 8. Normal probability plots of MRR

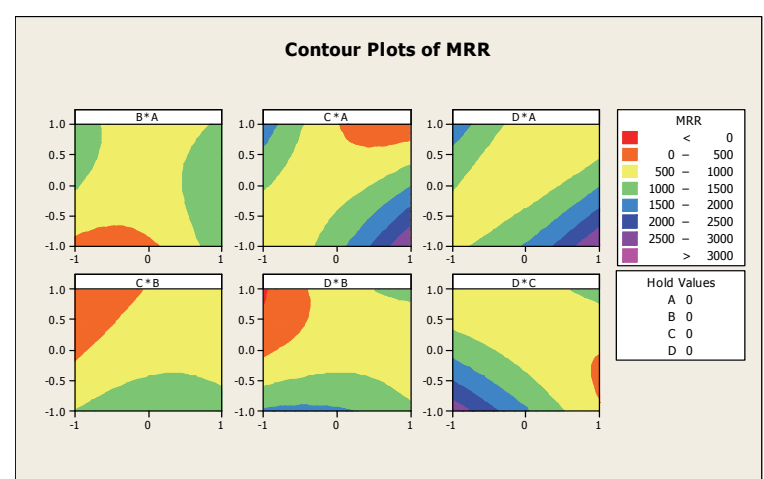

Fig. 9. Contour plots of MRR 
Table 5

Analysis of Variance of MRR

\begin{tabular}{|c|c|c|c|c|c|}
\hline Source & DF & Adj SS & Adj MS & F-Value & P-Value \\
\hline Regression & 14 & 17757533 & 1268395 & 1.38 & 0.291 \\
\hline Linear & 4 & 4864353 & 1268395 & 1.32 & 0.317 \\
\hline $\mathbf{A}$ & 1 & 560650 & 560650 & 0.61 & 0.45 \\
\hline B & 1 & 372002 & 372002 & 0.40 & 0.537 \\
\hline $\mathbf{C}$ & 1 & 2028285 & 2028285 & 2.21 & 0.163 \\
\hline D & 1 & 1903416 & 1903416 & 2.07 & 0.176 \\
\hline Square & 4 & 2564554 & 641139 & 0.70 & 0.608 \\
\hline $\mathbf{A} \times \mathbf{A}$ & 1 & 1110488 & 1110488 & 1.21 & 0.293 \\
\hline $\mathbf{B} \times \mathbf{B}$ & 1 & 273571 & 273571 & 0.30 & 0.595 \\
\hline $\mathbf{C} \times \mathbf{C}$ & 1 & 88453 & 88453 & 0.10 & 0.762 \\
\hline $\mathbf{D} \times \mathbf{D}$ & 1 & 698701 & 1721437 & 0.76 & 0.400 \\
\hline Interaction & 6 & 10328625 & 0.30671 & 1.87 & 0.167 \\
\hline $\mathbf{A} \times \mathbf{B}$ & 1 & 352346 & 352346 & 0.38 & 0.547 \\
\hline $\mathbf{A} \times \mathbf{C}$ & 1 & 4203013 & 4203013 & 4.57 & 0.054 \\
\hline $\mathbf{A} \times \mathbf{D}$ & 1 & 2985854 & 2985854 & 3.25 & 0.097 \\
\hline $\mathbf{B} \times \mathbf{C}$ & 1 & 16352 & 16352 & 0.02 & 0.896 \\
\hline $\mathbf{B} \times \mathbf{D}$ & 1 & 660359 & 660359 & 0.72 & 0.413 \\
\hline $\mathbf{C} \times \mathbf{D}$ & 1 & 2110700 & 2110700 & 2.30 & 0.156 \\
\hline Residual Error & 12 & 11027763 & 918980 & & \\
\hline Lack-of-Fit & 10 & 8436142 & 8436142 & 0.65 & 0.738 \\
\hline Pure Error & 2 & 2591621 & 1295811 & & \\
\hline Total & 26 & 28785296 & & & \\
\hline
\end{tabular}

\section{Artificial Neural Network}

Artificial Neural Networks (ANNs) are simple electronic devices modelled after the neural structure of the brain. ANNs are powerful tools for many complex applications such as optimization, system identification and pattern reorganization. ANNs are capable to learn from experiments and to perform non-linear mappings. The processing elements of neural networks are called artificial neurons, or nodes. ANN consists of input layers, which are multiplied by weights, and then evaluated by a mathematical mapping which computes the activation of the neuron. Another function determines the output of the artificial neuron. The artificial neurons of ANNs process the information. Neural networks are categorized by their structure, activation functions and training algorithms. Each type of neural networks has its own input-output characteristics; therefore, it could be applied only in some specific processes. In this one, a neural network is employed for modelling the MRR and the Ra in the EDM process. One of artificial neural networks, i.e., Back-Propagation Neural Network (BPNN) is discussed. The BPNN model consists of an input layer, one or two hidden layers, and an output layer in a forward multi-layer neural network (Fig. 10).

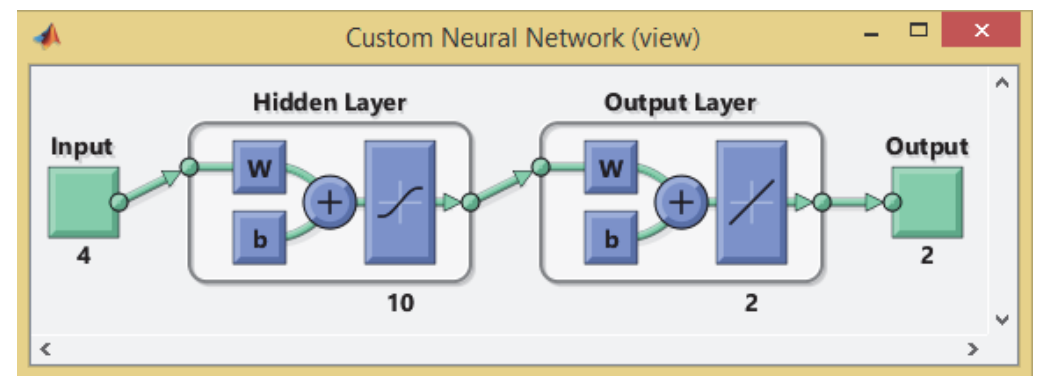

Fig. 10. Customized Neural network structure

Neural networks are categorized by their structure, activation functions and training algorithms. Each type of neural networks has its own input-output characteristics; therefore, it could be applied only in some specific processes. In this one, a neural network is employed for modeling the MRR and the Ra in the AWJM process. 


\subsection{Optimization Approach}

The trained ANN model can determine the response parameters as a function of four different control (input) parameters, i.e., MRR, abrasive flow rate, SOD, traverse speed. An attempt was made to generate the highest number of input, output parameter combinations to get more number of optimum points. The input parameters (four in numbers) were divided into all possible levels. These considerations resulted in 6050 possible input combinations. The developed ANN model was used to determine the MRR and Ra for all possible levels of the 6050 combinations. Finally, the results of this study proposed best of these combinations.

\section{Table 6}

Predicted output values using ANN

\begin{tabular}{ccccccc}
\hline S.NO & Pressure & $\begin{array}{c}\text { Abrasive } \\
\text { flow rate }\end{array}$ & SOD & $\begin{array}{c}\text { Traverse } \\
\text { speed }\end{array}$ & MRR & SR \\
\hline 1 & 3140 & 600 & 2 & 490 & 1129.026658 & 5.771710899 \\
2 & 3040 & 780 & 2.2 & 375 & 1129.256601 & 5.855212906 \\
3 & 3000 & 620 & 2 & 400 & 1201.265868 & 5.976404759 \\
4 & 3160 & 720 & 2.4 & 485 & 1202.297187 & 5.615578039 \\
5 & 3000 & 740 & 2.5 & 500 & 1203.485695 & 5.262118619 \\
6 & 3120 & 800 & 2.1 & 370 & 1204.138402 & 5.780498788 \\
7 & 3180 & 780 & 2.6 & 430 & 1204.277721 & 6.071839402 \\
8 & 3160 & 760 & 2.3 & 500 & 1205.123621 & 5.419318083 \\
9 & 3000 & 680 & 2.3 & 480 & 1754.905481 & 5.898562813 \\
10 & 3020 & 800 & 2.3 & 500 & 1758.282978 & 5.847318964 \\
11 & 3000 & 800 & 2.4 & 485 & 1827.16306 & 5.896483022 \\
12 & 3020 & 780 & 2.4 & 480 & 1831.315761 & 5.912730528 \\
13 & 3080 & 680 & 2.2 & 485 & 1862.845016 & 6.069668546 \\
14 & 3060 & 740 & 2.2 & 500 & 1864.782594 & 5.954993512 \\
15 & 3040 & 640 & 2.2 & 475 & 1866.067999 & 6.190420705 \\
16 & 3260 & 660 & 2 & 350 & 3371.011297 & 7.386846458 \\
\hline
\end{tabular}

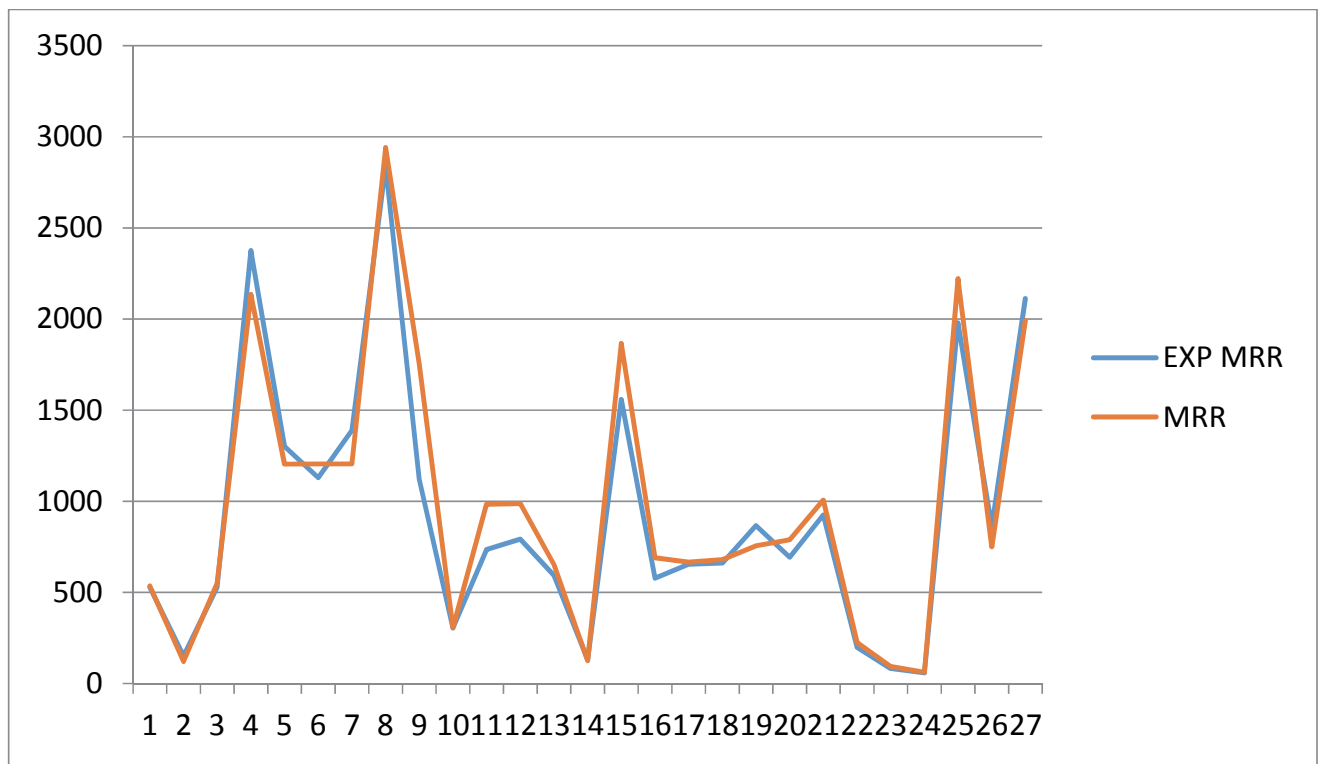

Fig. 11. Experimental MRR Vs ANN MR 


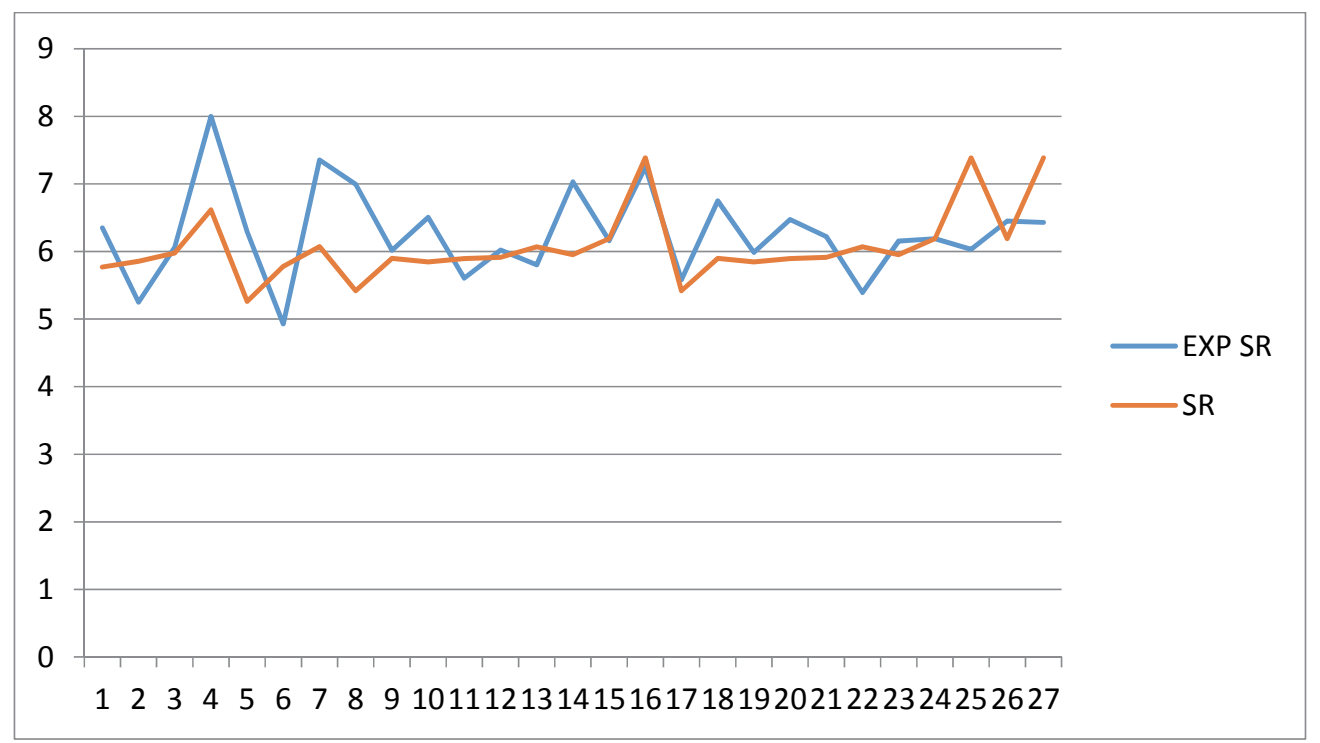

Fig. 12. Experimental SR VS ANN SR

Parameter which we have considered to compare the proposed ANN model result with experimental result is the regression analysis or the R-value. Fig. 13 shows the R values based on ANN model and the experimental data for the MRR and Ra. The solid line represents the best possible regression fit between targets and outputs for training, validation, testing and all data sets. The value of $\mathrm{R}$, which is shown in Fig. 13, represents the relation-ship between those two. In neural networks, $\mathrm{R}=1$ indicates the perfect match between targets and outputs. Since the net-works cannot be made to learn perfectly, the general value of $\mathrm{R}$ lies near to 1 . The closer its value to 1 , the better the neural network is. On the other hand, the value of $\mathrm{R}$ close to 0 indicates the nonlinear relationship between targets and outputs.

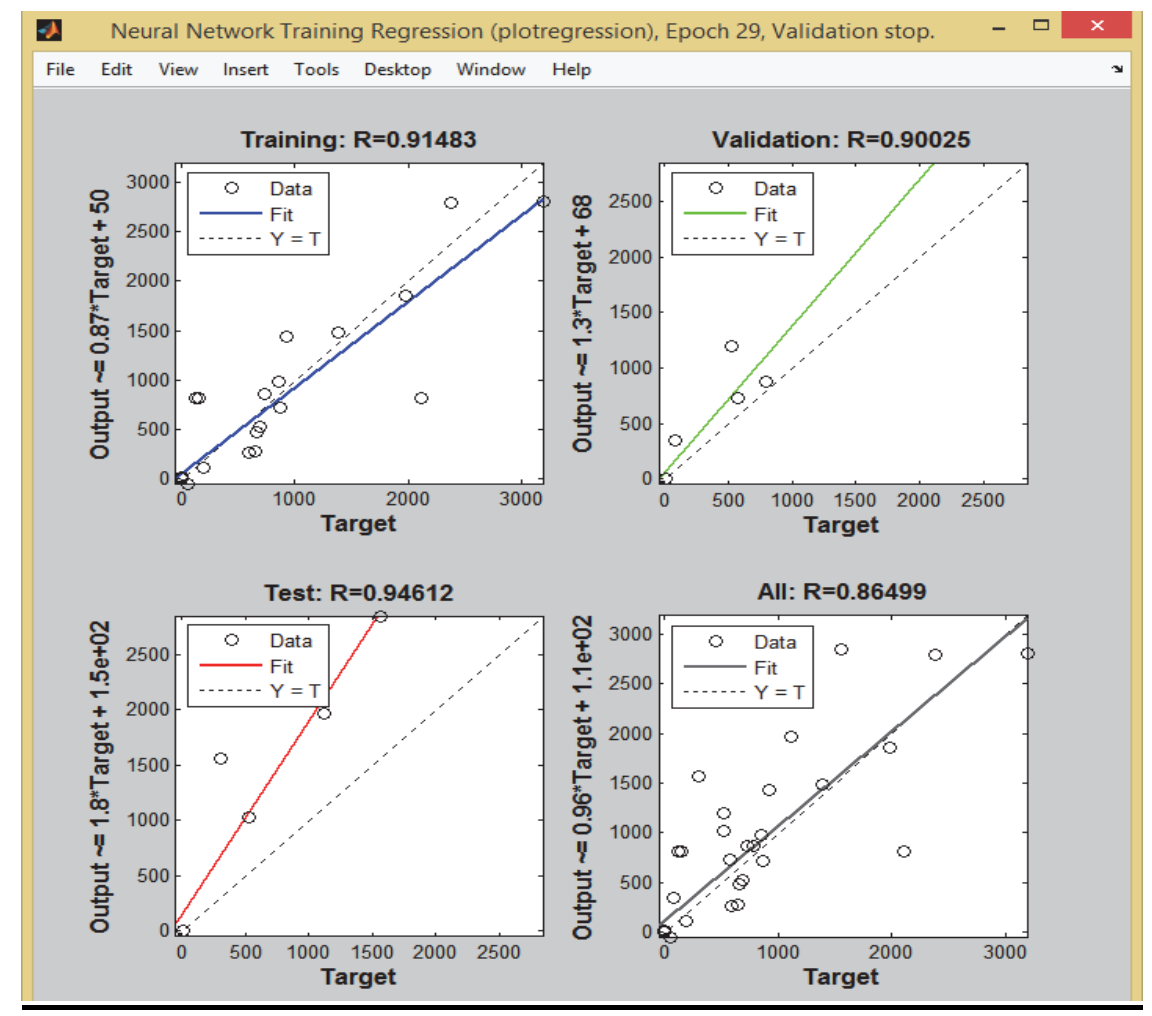

Fig. 13. Compressions between Target and Output of ANN 


\section{Conclusions}

The influence of AWJ machining parameters on responses are reported in results and discussion section. Based on results analysis, the following conclusions were drawn. Based on analysis, it was found that a linear increase of MRR as pressure increases. Abrasive flow rate doesn't have any significant impact on MRR. Both SOD and traverse speed has similar impact on MRR. Maximum material removal rate is achieved at high pressure and low SOD, traverse speed. It is concluded from counter plots that an optimum value of $2000-3000 \mathrm{~mm}^{3} / \mathrm{sec}$ of MRR can be achieved by setting pressure to $3600 \mathrm{bar}$, SOD $2 \mathrm{~mm}$ and traverse speed to $350 \mathrm{~mm} / \mathrm{min}$. MRR is observed to be minimum at low abrasive flow rate and high SOD, traverse speed.

It is concluded that surface roughness is prominently affected by pressure followed by SOD and feed rate. Surface roughness decreases with increase in standoff distance. High surface finish is obtained at low feed rate and high standoff distance. An optimal value of surface roughness of 5-6 $\mu \mathrm{m}$ is obtained at $3 \mathrm{~mm}$ standoff distance and at a feed rate of $350 \mathrm{~mm} / \mathrm{min}$. At low pressure and low abrasive flowrate surface roughness expected at very high. When compared to predict with experimental response, both are showing good agreement.

\section{References}

Assarzadeh, S., Ghoreishi, M., \& Shariyyat, M. (2010). Response surface methodology approach to process modeling and optimization of powder mixed electrical discharge machining (PMEDM). In Proceedings of the 16th International Symposium on Electromachining (ISEM-XVI) April (pp. 19-23).

Azmir, M. A., \& Ahsan, A. K. (2009). A study of abrasive water jet machining process on glass/epoxy composite laminate. Journal of Materials Processing Technology, 209(20), 6168-6173.

Borkowski, P. (2004). Theoretical and experimental basis of hydro-jet surface treatment. Publ. Koszalin University of Technology.

Box, G. E., \& Draper, N. R. (2007). Response surfaces, mixtures, and ridge analyses (Vol. 649). John Wiley \& Sons.

Fenggang, L., Geskin, E. S., \& Tismenetskiy, L. (1996). Feasibility study of abrasive waterjet polishing. 13th Int. In Conf. on Jetting Technology. Sardinia(pp. 709-723).

Folkes, J. (2009). Waterjet-An innovative tool for manufacturing. Journal of Materials Processing Technology, 209(20), 6181-6189.

Hashish, M. (1987). Turning With Abrasive-Waterjets--a First Investigation. J. Eng. Ind.(Trans. ASME), 109(4), 281-290.

Hashish, M. (1989). An investigation of milling with abrasive-waterjets. ASME J. Eng. Ind, 111(2), 158-166.

Ibraheem, H. M. A., Iqbal, A., \& Hashemipour, M. (2015). Numerical optimization of hole making in GFRP composite using abrasive water jet machining process. Journal of the Chinese Institute of Engineers, 38(1), 66-76.

Jegaraj, J. J. R., \& Babu, N. R. (2007). A soft computing approach for controlling the quality of cut with abrasive waterjet cutting system experiencing orifice and focusing tube wear. Journal of Materials Processing Technology, 185(1), 217-227.

Khan, A. A., \& Haque, M. M. (2007). Performance of different abrasive materials during abrasive water jet machining of glass. Journal of materials processing technology, 191(1), 404-407.

Lemma, E., Chen, L., Siores, E., \& Wang, J. (2002). Optimising the AWJ cutting process of ductile materials using nozzle oscillation technique. International Journal of Machine Tools and Manufacture, 42(7), 781-789.

Liu, D., Huang, C., Wang, J., Zhu, H., Yao, P., \& Liu, Z. (2014). Modeling and optimization of operating parameters for abrasive waterjet turning alumina ceramics using response surface methodology combined with Box-Behnken design. Ceramics International, 40(6), 7899-7908.

Lu, Y., Li, X., Jiao, B., \& Liao, Y. (2005). Application of artificial neural networks in abrasive waterjet cutting process. Advances in Neural Networks-ISNN 2005, 982-982.

Mishra, P. K. (2002). Non-conventional machining processes. Published by NK Mehra (Naroja publishing house), 3 . 
Momber, A. W., \& Kovacevic, R. (1997). Test parameter analysis in abrasive water jet cutting of rocklike materials. International Journal of Rock Mechanics and Mining Sciences, 34(1), 17-25.

Myers, R. H., Montgomery, D. C., \& Anderson-Cook, C. M. (2016). Response surface methodology: process and product optimization using designed experiments. John Wiley \& Sons.

Nagdeve, L., Chaturvedi, V., \& Vimal, J. (2012). Implementation of Taguchi approach for optimization of abrasive water jet machining process parameters. International Journal of Instrumentation, Control and Automation, 1(3), 4.

Patel, S. R., \& Shaikh, A. A. (2013). Control and measurement of abrasive flow rate in an Abrasive Waterjet Machine. International journal of innovative Research in Science, Engineering and Technology, ISSN, 2319-8753.

Ramprasad, U. G., \& Kamal, H. (2015). Optimization MRR of Stainless steel 403 in abrasive water jet machining using ANOVA and Taguchi method. International Journal of Engineering Research and Applications, 5(5), 86-91.

Shanmugam, D. K., \& Masood, S. H. (2009). An investigation on kerf characteristics in abrasive waterjet cutting of layered composites. Journal of materials processing technology, 209(8), 38873893.

Shanmugam, D. K., Wang, J., \& Liu, H. (2008). Minimisation of kerf tapers in abrasive waterjet machining of alumina ceramics using a compensation technique. International Journal of Machine Tools and Manufacture, 48(14), 1527-1534.

Srinivasu, D. S., \& Babu, N. R. (2008). A neuro-genetic approach for selection of process parameters in abrasive waterjet cutting considering variation in diameter of focusing nozzle. Applied Soft Computing, 8(1), 809-819.

Srinivasu, D. S., Babu, N. R., Srinivasa, Y. G., Louis, H., Peter, D., \& Versemann, R. (2005, August). Genetically evolved artificial neural networks built with sparse data for predicting depth of cut in abrasive water jet cutting. In Proceedings American Water Jet Conference. Houston, Texas (pp. 116).

Vundavilli, P. R., Parappagoudar, M. B., Kodali, S. P., \& Benguluri, S. (2012). Fuzzy logic-based expert system for prediction of depth of cut in abrasive water jet machining process. KnowledgeBased Systems, 27, 456-464.

Yong, Z., \& Kovacevic, R. (1997). Modeling of jetflow drilling with consideration of the chaotic erosion histories of particles. Wear, 209(1-2), 284-291.

Zhao, C. Y., Gong, H., Fang, F. Z., \& Li, Z. J. (2013). Experimental study on the cutting force difference between rotary ultrasonic machining and conventional diamond grinding of K9 glass. Machining Science and Technology, 17(1), 129-144.

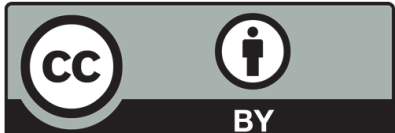

(C) 2018 by the authors; licensee Growing Science, Canada. This is an open access article distributed under the terms and conditions of the Creative Commons Attribution (CC-BY) license (http://creativecommons.org/licenses/by/4.0/). 